\title{
Knowledge about prevention and control of infection related to health care: hospital context
}

\author{
Conhecimento sobre prevenção e controle de infecção relacionada à assistência à saúde: \\ contexto hospitalar
}

Andréa Mara Bernardes da Silva ${ }^{1}$, Denise de Andrade ${ }^{1}$, Anneliese Domingues Wysocki ${ }^{2}$, Adriana Cristina Nicolussi ${ }^{3}$, Vanderlei José Haas ${ }^{3}$, Mário Alfredo Silveira Miranzi ${ }^{3}$

\begin{abstract}
Objective: to identify the knowledge of health professionals about the recommendations for prevention and control of healthcare-related infection. Methods: cross-sectional study, conducted with 308 nurses, technicians, doctors and physiotherapists in public teaching hospital. Instrument constructed and validated was used for data collection. We performed a descriptive analysis, association measures and the Student $\mathrm{t}$ test. Results: the comparison of means to precautions standard averages indicated that there was no significant difference between the occupational categories. The association of specific knowledge scores with time of training, performance in the institution and professional performance, show that the recommendations knowledge is different between the categories. For some professionals the more training time and professional performance, the less knowledge. A variable with respect to respiratory tract showed statistically significant $(\mathrm{p}=0.044)$. Conclusion: there was adequate knowledge about preventive recommendations although limited in specific fields.
\end{abstract}

Descriptors: Knowledge; Cross Infection; Disease Prevention; Health Personnel.

Objetivo: identificar o conhecimento dos profissionais de saúde acerca das recomendações para prevenção e controle de infecção relacionada à assistência à saúde. Métodos: estudo transversal, realizado com 308 enfermeiros, técnicos, médicos e fisioterapeutas em hospital público de ensino. Utilizou-se instrumento construído e validado para coleta de dados. Realizou-se análise descritiva, medidas de associação, e teste $t$ de Student. Resultados: a comparação das médias para medidas de precaução padrão indicou que não houve diferença significativa entre as categorias profissionais. A associação dos escores de conhecimento específico com tempo de formação, de atuação na instituição e atuação profissional, constatou que o conhecimento das recomendações se apresenta diferente entre as categorias. Para alguns profissionais quanto maior tempo de formação, e atuação profissional, menor é o conhecimento. Uma variável em relação ao trato respiratório apresentou-se estatisticamente significante $(\mathrm{p}=0,044)$. Conclusão: houve conhecimento adequado sobre as recomendações preventivas, contudo este foi limitado em domínios específicos.

Descritores: Conhecimento; Infecção Hospitalar; Prevenção de Doenças; Profissionais da Saúde.

\footnotetext{
${ }^{1}$ Universidade de São Paulo. Ribeirão Preto, SP, Brazil.

${ }^{2}$ Universidade Federal do Mato Grosso do Sul. Três Lagoas, MS, Brazil.

${ }^{3}$ Universidade Federal do Triângulo Mineiro. Uberaba, MG, Brazil.
} 


\section{Introduction}

Infection related to health care, especially in hospitals, has been pointed to as a risk that threatens patient safety ${ }^{(1-2)}$. It is among the leading causes of mortality and morbidity, representing an important public health problem. This problem is a challenge for scientific-technological advances and mobilizes the attention of practitioners, researchers, national and international organizations that seek the effectiveness of prevention and control measures ${ }^{(2)}$.

The health care-related infection is considered an epiphenomenon that has grounded discussions about the institutionalization of patient safety initiatives and reduction of cases at hospitals, leading to studies about human error, accidents and prevention ways, to improve care ${ }^{(3)}$. However, although there are advances in the area, there are still increasing failures that directly impact the quality and safety of the assistance practices that require changes in professional behavior and attitudes ${ }^{(4)}$.

The importance of the evaluation of the knowledge of the professionals and the implementation of educational programs aimed at the prevention of healthcare-related infections go against studies that indicate the level of knowledge of health professionals on preventive measures of nosocomial infection as directly proportional to their adoption in work routine $e^{(1,5)}$, since there is still a great dichotomy between what is recommended and practiced at health services.

In this sense, it is of fundamental importance to identify the knowledge of different health professionals on the proposed recommendations for prevention and control of healthcare-related infection for the development of prevention strategies, so necessary to improve the quality of the assistance provided. Moreover, that knowledge enables health professionals to recognize causes and types of infection and the main activities that put patients at risk situations.

Thus, the objective of this study was to identify the knowledge of health professionals about the recommendations to prevent and control healthcare-related infection.

\section{Methods}

It is a descriptive, cross-sectional study, conducted with health professionals who worked in a public university and teaching hospital, in a large municipality of Minas Gerais, Brazil. The place of study offers service of high complexity and has 290 beds, 20 beds in the children's intensive care unit, ten in Adult intensive care unit and ten in the Coronary intensive care unit, which are used as field of clinical teaching for undergraduate and technical courses in health.

As inclusion criteria were determined: being a nurse, technician and/or nursing assistant, physician and physiotherapist; working directly on assistance to patients and professionals who were present in the range of service in the period of data collection. Professionals who performed exclusively administrative functions, who were away or on vacation in the period of data collection and no found after three attempts, were excluded.

To calculate the sample size the number of effective professionals in the hospital was surveyed. From this finite population of 1,135 professionals and considering the parameters: prevalence $50.0 \%$ confidence interval $95.0 \%$, accuracy $4.0 \%$ and loss $20.0 \%$ we obtained a sample of 487 professionals. The participants were selected through convenience sampling. There were some professionals who were not found after three attempts and some refusals so, the final sample consisted of 308 (63.2\%) health professionals.

Data collection occurred through the application of an instrument to professionals. The construction of the instrument was carried out in two stages: selection, construction and justification of content and content validation by experts. At first, we used the criteria set out by the National Agency of Surveillan$\mathrm{ce}^{(6)}$ and Center for diseases control and prevention ${ }^{(7-11)}$ about measures to prevent the transmission of disea- 
ses, priority recommendations in relation to urinary catheterization, intravascular catheterization, surgical site, mechanical ventilation and standard precautions. Items about hands hygiene and the use of personal protective equipment were considered as standard precautions. To check the clarity and applicability of the instrument a pilot study was conducted with ten health professionals from two sectors.

The instrument included two sections: one related to socio-demographic, economic and professional information of participants (13 items) and the second on professional practices related to the control and prevention of health care-related infection, specific to each category, which is sub-categorized into five parts: standard precautions (9 items); Urinary catheters (eight items for nurses and nursing technicians and seven for doctors); Intravascular catheters (ten items for nurses and nursing technicians and seven for doctors); Surgical site (five items for nurses and nursing technicians and 12 to doctors) and mechanical ventilation (14 items for nurses and nursing technicians; nine items for physicians and 11 for physiotherapists).

The data was tabulated in an Excel ${ }^{\circledR}$ spreadsheet for Windows $\mathrm{XP} \AA$, validated by double-entry and subsequently exported and processed in the program Statistical Package for the Social Sciences version 17.0.

The analysis of the knowledge of health professionals took place through the construction of scores of knowledge according to the domain analyzed, which were calculated from the average of the items answered correctly (number of correct answers/ number of domain items) x 100]. It was considered as satisfactory knowledge ("good knowledge" and "good attitude") a percentage of $75.0 \%$ of suitable responses related to knowledge and unsatisfactory those who obtained percentage less than $75.0 \%$.

It is important to highlight that physiotherapists were only assessed in relation to measures of prevention and control of healthcare-related infection about the items: "standard precaution measures" and "mechanical ventilation", since this category does not have professional responsibility in terms of urinary and venous catheters and surgical site.

To observe differences between the knowledge of occupational categories we used the Student's T-Test. Pearson Correlation was used between the knowledge scores, with training time, professional experience and professional performance at the institution between the different professional categories according to the normality of the data (Kolmogorov Smirnov) and homogeneity of variances (Levene). It was considered a significance level of 5.0\%.

The study complied with the formal requirements contained in the national and international regulatory standards for research involving human beings.

\section{Results}

308 health professionals participated in this study distributed among: nurses (25/8.1\%), technicians and nursing assistants (174/56.5\%), doctors (90/29.2\%) and physiotherapists (19/6.2\%). With respect to education, $250(83.9 \%)$ graduated more than three years ago, with a professional experience in the institution of more than three years (220/72.4\%) with experience in both 12 or 24 hours shifts (86/28.0\%); in nocturnal periods (84/27.5\%;) in the morning (70/22.9\%) and afternoon (66/21.6\%). Analyzing the doctors' work, 79 (91.9\%) reported working on shift rotation schedule. With respect to monthly income, $77(25.0 \%)$ received one to two minimum salaries, 95 (30.9\%) from three to four wages, $44(14.3 \%)$ from five to six salaries and 86 (27.9\%) had income exceeding six minimum wages. There was a predominance of the female gender $(23 / 72.4 \%)$. The average age of participants was of 37.64 years old, ranging from 22 to 63 years.

To present the success related to standard precaution measures the categories nurses, technicians 
and nursing auxiliaries were grouped in nursing professionals to better describe the outcome and make it easier to understand. The analysis of variance of the scores between the groups indicated that there was no significant difference between the professional categories $(\mathrm{p}=0.111)$. Close average scores were observed, indicating homogeneity in knowledge of the different professional categories surveyed, the average responses ranged from 77.19 for physiotherapists; 80.12 for doctors and 82.57 for nursing professionals.

Table 1 shows the scores of specific knowledge per professional category. Nursing professionals showed unsatisfactory average for the domains related to the surgical site and intravascular catheters. The success average was worst among nurses when compared to technicians and nursing assistants.
We observed weak correlation between the technicians' and nursing assistants' professional training and the knowledge score on the surgical site, showing that the longer, the better the knowledge. There was no statistically significant association between the performance in institution of technicians and nursing assistants and the score of knowledge on mechanical ventilation $(\mathrm{p}=0.044)$ (Table 2$)$.

Both for nurses working in high-risk (critical/ semi critical areas) and low risk areas (non-critical areas) for hospital infection we observed knowledge on "intravascular Catheters" scores inferior to technicians and nursing assistants. The item about "mechanical ventilation" showed that only the medical category that operates in low-risk area showed superior knowledge than other categories (Table 3).

Table 1 - Scores of specific knowledge about recommendations for prevention and control of healthcare-related infection according to the professional category

\begin{tabular}{|c|c|c|c|c|c|}
\hline Professional/knowledge scores & Minimum & Maximum & Average & Medium & Standard deviation \\
\hline \multicolumn{6}{|l|}{ Nurse $(n=25)$} \\
\hline Urinary catheters & 37.5 & 100.0 & 82.5 & 87.5 & 14.9 \\
\hline Intravascular catheters & 40.0 & 90.0 & 59.2 & 60.0 & 14.1 \\
\hline Surgical site & - & 80.0 & 44.0 & 40.0 & 21.6 \\
\hline Mechanical ventilation & 50.0 & 100.0 & 81.7 & 85.7 & 11.1 \\
\hline \multicolumn{6}{|c|}{ Technician and Nursing assistant $(n=174)$} \\
\hline Urinary catheters & 37.5 & 100.0 & 80.4 & 87.5 & 11.2 \\
\hline Intravascular catheters & 10.0 & 100.0 & 62.6 & 60.0 & 15.3 \\
\hline Surgical site & - & 100.0 & 46.9 & 40.0 & 20.2 \\
\hline Mechanical ventilation & 21.4 & 100.0 & 76.0 & 78.6 & 14.5 \\
\hline \multicolumn{6}{|l|}{ Doctor $(n=90)$} \\
\hline Urinary catheters & - & 100.0 & 80.6 & 85.7 & 19.4 \\
\hline Intravascular catheters & - & 100.0 & 76.2 & 85.7 & 19.9 \\
\hline Surgical site & 25.0 & 100.0 & 79.0 & 83.3 & 16.7 \\
\hline Mechanical ventilation & - & 100.0 & 74.2 & 77.8 & 19.0 \\
\hline Physiotherapist ( $n=19$ ) & - & 54.6 & 100.0 & 84.2 & 91.0 \\
\hline Mechanical ventilation & 54.6 & 100.0 & 84.2 & 91.0 & 11.3 \\
\hline
\end{tabular}


Table 2 - Correlation between knowledge scores, professional training time, institution working time and professional performance of intra-hospital health professionals

\begin{tabular}{|c|c|c|c|c|c|c|}
\hline \multirow{2}{*}{ Professional/Knowledge scores } & \multicolumn{2}{|c|}{ Professional training time } & \multicolumn{2}{|c|}{ Institution working time } & \multicolumn{2}{|c|}{ Professional performance time } \\
\hline & $\mathbf{r}^{*}$ & $\mathbf{p}^{* *}$ & $\mathbf{r}$ & $\mathbf{p}$ & $\mathbf{r}$ & $\mathbf{p}$ \\
\hline \multicolumn{7}{|l|}{ Nurse $(n=25)$} \\
\hline Urinary catheters & -0.13 & 0.564 & 0.08 & 0.726 & -0.15 & 0.469 \\
\hline Intravascular catheters & -0.25 & 0.245 & -0.13 & 0.592 & -0.06 & 0.756 \\
\hline Surgical site & 0.26 & 0.229 & 0.14 & 0.575 & 0.33 & 0.117 \\
\hline Mechanical ventilation & 0.08 & 0.704 & -0.16 & 0.507 & 0.08 & 0.710 \\
\hline \multicolumn{7}{|c|}{ Technician and Nursing assistant $(\mathrm{n}=174)$} \\
\hline Urinary catheters & -0.07 & 0.346 & -0.04 & 0.618 & -0.03 & 0.710 \\
\hline Intravascular catheters & -0.07 & 0.361 & -0.02 & 0.809 & -0.01 & 0.839 \\
\hline Surgical site & 0.14 & 0.071 & 0.03 & 0.666 & 0.10 & 0.191 \\
\hline Mechanical ventilation & -0.09 & 0.228 & -0.16 & 0.044 & -0.09 & 0.235 \\
\hline \multicolumn{7}{|l|}{ Doctor $(n=90)$} \\
\hline Urinary catheters & 0.12 & 0.260 & 0.06 & 0.535 & 0.04 & 0.661 \\
\hline Intravascular catheters & 0.07 & 0.519 & -0.02 & 0.570 & 0.03 & 0.745 \\
\hline Surgical site & 0.07 & 0.512 & 0.03 & 0.761 & -0.04 & 0.680 \\
\hline Mechanical ventilation & -0.09 & 0.398 & -0.15 & 0.153 & -0.12 & 0.274 \\
\hline \multicolumn{7}{|l|}{ Physiotherapist (n=19) } \\
\hline Mechanical ventilation & -0.19 & 0.464 & -0.05 & 0.842 & -0.25 & 0.308 \\
\hline
\end{tabular}

Table 3 - Comparison of knowledge scores among the professionals who work in areas of high and low risk for infection related to healthcare

\begin{tabular}{|c|c|c|c|c|c|c|c|c|c|}
\hline \multirow{2}{*}{$\begin{array}{l}\text { Professional/Knowledge } \\
\text { scores }\end{array}$} & \multicolumn{4}{|c|}{ High risk } & \multicolumn{4}{|c|}{ Low Risk } & \multirow[b]{2}{*}{$\mathbf{p}^{*}$} \\
\hline & Minimum & Maximum & Average & $\begin{array}{l}\text { Standard } \\
\text { deviation }\end{array}$ & Minimum & Maximum & Average & $\begin{array}{l}\text { Standard } \\
\text { deviation }\end{array}$ & \\
\hline \multicolumn{10}{|l|}{ Nurse $(n=25)$} \\
\hline Urinary catheters & 37.5 & 100.0 & 83.1 & 15.3 & 62.5 & 100.0 & 81.2 & 14.9 & 0.780 \\
\hline Intravascular catheters & 40.0 & 80.0 & 58.2 & 12.9 & 40.0 & 90.0 & 61.2 & 17.3 & 0.629 \\
\hline Surgical site & 20.0 & 80.0 & 45.9 & 18.4 & - & 80,0 & 40.0 & 28.3 & 0.537 \\
\hline Mechanical ventilation & 71.4 & 100.0 & 84.9 & 7.1 & 50.0 & 92.9 & 75.0 & 15.3 & 0.118 \\
\hline $\begin{array}{l}\text { Technician and Nursing } \\
\text { assistant }(\mathrm{n}=174)\end{array}$ & & & & & & & & & \\
\hline Urinary catheters & 50.0 & 100.0 & 80.1 & 10.1 & 37.5 & 100.0 & 81.0 & 13.1 & 0.599 \\
\hline Intravascular catheters & 30.0 & 90.0 & 61.7 & 14.1 & 10.0 & 100.0 & 64.5 & 17.4 & 0.283 \\
\hline Surgical site & - & 80.0 & 45.2 & 18.7 & - & 100.0 & 50.3 & 22.9 & 0.128 \\
\hline Mechanical ventilation & 21.4 & 100.0 & 75.6 & 14.5 & 35.7 & 100.0 & 76.9 & 14.6 & 0.540 \\
\hline \multicolumn{10}{|l|}{ Doctor $(n=90)$} \\
\hline Urinary catheters & - & 100.0 & 82.4 & 19.1 & - & 100.0 & 78.6 & 19.8 & 0.349 \\
\hline Intravascular catheters & 42.9 & 100.0 & 75.9 & 15.3 & - & 100.0 & 76.5 & 24.2 & 0.880 \\
\hline Surgical site & 25.0 & 100.0 & 79.5 & 16.6 & 33.3 & 100.0 & 78.4 & 16.9 & 0.748 \\
\hline Mechanical ventilation & 11.1 & 100.0 & 77.3 & 16.8 & - & 88.9 & 70.6 & 20.8 & 0.096 \\
\hline \multicolumn{10}{|l|}{ Physiotherapist ( $n=19$ ) } \\
\hline Mechanical ventilation & 72.7 & 90.9 & 86.8 & 6.2 & 54.5 & 100.0 & 80.7 & 15.7 & 0.327 \\
\hline
\end{tabular}




\section{Discussion}

This research has some limitations, mainly related to the outline used. Studies of transverse type do not allow participants' follow-up, which would help to identify knowledge learnt over the years. In addition, the fact that it was conducted in a single institution makes it difficult to extrapolate the data.

Assessing the knowledge of professionals contribute to implement measures and health education programs, especially in the case of diseases that cause significant impact, as the infection related to healthcare forged in the practices of health assistance ${ }^{(12)}$.

In this research, we noticed that the theoretical knowledge about standard precautions of the participants is appropriate, although the prevalence of certain items answers is inadequate. Among the categories worked, technicians and nursing assistants obtained higher percentages of error for questions about hands hygiene, which can expose the client to risk situations ${ }^{(2,13-14)}$.

The use of precautionary measures is linked to knowledge and attitudes of staff professionals, influenced by beliefs in health. A research conducted in Brazil showed that low adherence to precautionary measures by health professionals may be related to various aspects of human behavior, including individual factors, such as risk perception to recognize occupational exposure situations and adopt protective measures $^{(15)}$.

On the scores of specific knowledge for each intra-hospital professional category about the recommendations to prevent and control infection related to the urinary tract, the nurses showed greater knowledge, while the other professionals presented adequate knowledge, with an average of more than 75 .

This research recorded that the longer the training time and performance in the institution, the less knowledge about the recommendations proposed, indicating the necessity and importance of permanent and continuing education for health professionals $^{(15-16)}$.

In the field referring to intravascular catheters, infections related to insertion of vascular access, even smaller when compared to bloodstream, show relevant considerations that may indicate contamination of the device insertion place and point to the possibility of a specific preventive intervention. In addition, they are indicators of care quality, applied in and out critical and non-critical environments; they measure quality of assistance and impact directly and indirectly, raise the cost of hospitalization and increase mortality rates. It should be noted that the prevention and control of infections related to vascular catheters is the responsibility of nursing staff ${ }^{(17)}$.

About surgical site-related items, nursing professionals showed unsatisfactory average for that domain. It should be highlighted that the infection related to the surgical site represents one of the main risks to patient safety in health services in Brazil and occupies the third place among the healthcare-related infections, corresponding to an amount from 14 to $16.0 \%$ of those found in hospitalized patients ${ }^{(6)}$.

A national research that assessed pre-surgical and intra-surgical practices adopted by medical and nursing staff, aiming at preventing surgical infections, identified partial adherence to world recommendations; the measures to which they do not adhere indicated ignorance or negligence of professionals, reaffirming the need for professional training, in order to improve the quality of the assistance and the safety of surgical patients ${ }^{(18)}$.

As for the items related to mechanical ventilation, the descriptive analysis showed similar responses with good success percentages. The mechanical ventilator is the main risk factor for pneumonia associated with mechanical ventilation ${ }^{(19)}$. This knowledge is of utmost importance since the infections related to the use of mechanical ventilator correspond to $15.0 \%$ of infections in hospitals. The occurrence increases 
the period of hospitalization, morbidity and mortality rates as well as hospital costs ${ }^{(4)}$.

Although the knowledge identified has been satisfactory for most specific fields among different occupational categories, few items stood out by offering low averages. The data reaffirm the need for training of health professionals to establish processes of competences construction (knowledge, skills and attitudes) required to a secure and qualified healthcare.

\section{Conclusion}

The general knowledge of the participants on the recommendations proposed by the Center for $\mathrm{di}^{-}$ seases control and prevention to prevent and control healthcare-related infection in hospitals was appropriate. However, it was limited in some situations, which represents a factor of great concern, especially in areas of elevated risk for hospital infection. It was observed that knowledge is different among the categories, for some professionals the longer the training and professional performance, the less the knowledge presented in scores and specific domains.

\section{Collaborations}

Silva AMB and Miranzi MAS contributed to the project design, analysis and interpretation of data, article writing, critical analysis of relevant content and final approval of the version to be published. Haas VJ contributed to the analysis and interpretation of data and writing the article. Andrade D, Wysocki AD and Nicolussi AC contributed in article writing and final approval of the version to be published.

\section{References}

1. Menegueti MG, Canini SRMS, Bellissimo-Rodrigues F, Laus AM. Evaluation of Nosocomial Infection Control Programs in health services. Rev LatinoAm Enfermagem. 2015; 23(1):98-105. doi: http:// dx.doi.org/10.1590/0104-1169.0113.2530
2. Barbosa TP, Oliveira GAA, Lopes MNA, Poletti NAA, Beccaria LM. Care practices for patient safety in an intensive care unit. Acta Paul Enferm. 2014; 27(3):243-8. doi: http://dx.doi. org/10.1590/1982-0194201400041

3. Sousa AFL, Queiroz AAFLN, Oliveira LB, Valle ARMC, Moura MEB. Social representations of communityacquired infection by primary care professionals. Acta Paul Enferm. 2015; 28(5):454-9. doi: http:// dx.doi.org/10.1590/1982-0194201500076

4. Vituri DW, Évora YDM. Total Quality Management and hospital nursing: an integrative literature review. Rev Bras Enferm. 2015; 68(5):94552. doi: http://dx.doi.org/10.1590/00347167.2015680525i

5. Pérez-Pérez P,Herrera-Usagre M, Bueno-Cavanillas A, Alonso-Humada MS, Buiza-Camacho B, VázquezVázquez M. Hand hygiene: health professionals' knowledge and areas for improvement. Cad Saúde Pública. 2015; 31(1):149-60. doi: http://dx.doi. org/10.1590/0102-311X00106913

6. Ministério da Saúde (BR). Agência Nacional de Vigilância Sanitária. Critérios diagnósticos de infecção relacionada à assistência à saúde. Brasília: Ministério da Saúde; 2013.

7. Centers for Disease Control and Prevention. National Healthcare Safety Network (NHSN) Manual. Guidelines for preventing healthcare infections control practices advisory committee; HHS Action Plan to Prevent Healthcare-Associated Infections [Internet]. 2003 [cited Jan 6]. Available from:https://www.cdc.gov/infectioncontrol/ guidelines/pneumonia/index.html

8. Centers for Disease Control and Prevention. The National Healthcare Safety Network (NHSN) Manual.Guidelines and procedures for monitoringSurgical Site Infection (SSI) Event. [Internet]. 2010 [cited Jan 6]. Available from: https://www. cdc.gov/nhsn/pdfs/pscmanual/9pscssicurrent. pdf

9. Centers for Disease Control and Prevention. The National Healthcare Safety Network (NHSN) Manual. Guidelines for prevention of catheterassociated urinary tract infection [Internet] 2009 [cited Jan 6].. Available from: https://www. cdc.gov/infectioncontrol/pdf/guidelines/cautiguidelines.pdf 
10. Centers for Disease Control and Prevention. The National Healthcare Safety Network (NHSN) Manual. Guideline for isolation precautions: preventing transmission of infectious agents in healthcare settings. [Internet]. 2007 [cited Jan 6]. Available from: https://www.cdc.gov/ infectioncontrol/pdf/guidelines/isolationguidelines.pdf

11. Centers for Disease Control and Prevention. The National Healthcare Infection Control Practices Advisory Committee. Guidelines for the prevention of intravascular catheter-related infections. [Internet]. 2011 [cited Jan 6]. Available from:https://www.cdc.gov/infectioncontrol/pdf/ guidelines/bsi-guidelines.pdf

12. Sousa AFL, Queiroz AAFLN, Oliveira LB, Moura MEB, Batista OMA, Andrade D. Social representations of biosecurity in nursing: occupational health and preventive care. Rev Bras Enferm. 2016; 69(5):864-71. doi: http://dx.doi. org/10.1590/0034-7167-2015-0114

13. Rosetti KAG, Tronchin DMR. Compliance of hand hygiene in maintaining the catheter for hemodialysis. Rev Bras Enferm. 2015; 68(6):1050-5. doi: dx.doi.org/10.1590/00347167.2015680608i

14. Santos TCR, Roseira CE, Piai-Morais TH, Figueiredo RM. Hand hygiene in hospital environments: use of conformity indicators. Rev Gaúcha Enferm. 2014; 35(1):70-7. doi: http://dx.doi.org/10.1590/19831447.2014.01.40930
15. Piai-Morais TH, Orlandi FS, Figueiredo RM. Factors influencing adherence to standard precautions among nursing professionals in psychiatric hospitals. Rev Esc Enferm USP. 2015; 49(3):473-80. doi: http://dx.doi.org/10.1590/ S0080-623420150000300016

16. Brand CI, Fontana RT. Biosafety in the perspective of nursing staff of Intensive Care Units. Rev Bras Enferm. 2014; 67(1):78-84. doi: http://dx.doi. org/10.5935/0034-7167.20140010

17. Batista OMA, Moreira RF, Sousa AFL, Moura MEB, Andrade D, Madeira MZA. Local complications of peripheral intravenous therapy and associated factors in Brazilian hospital. Rev Cuba Enferm. 2017; 33(3). In Press

18. Oliveira AC, Gama CS. Evalution of adherence to measures for the prevention of surgical site infections by the surgical team. Rev Esc Enferm USP. 2015; 49(5):767-74. doi: http://dx.doi. org/10.1590/S0080-623420150000500009

19. Batista OMA, Alexandria FED, Valle ARMC, Santo MSG, Madeira MZA, Sousa AFL. Sensitivity of embryos related to the pneumonia associated with the ventilation mechanics. Rev Pesqui Cuid Fundam on line [Internet]. 2014 [cited 2017 May 01]; 5(6):224-33. Available from: http://www. seer.unirio.br/index.php/cuidadofundamental/ article/view/3447 